\title{
Combined femoral and axillary perfusion strategy for Stanford type a aortic dissection repair
}

\author{
Ling-chen Huang ${ }^{\dagger}$, Qi-chen $\mathrm{Xu}^{\dagger}$, Dao-zhong Chen, Xiao-fu Dai and Liang-wan Chen ${ }^{*}$
}

\begin{abstract}
Background: The optimal cannulation strategy in surgery for Stanford type A aortic dissection is critical to patient survival but remains controversial. Different cannulation strategies have their own advantages and drawbacks during cardiopulmonary bypass. Our centre used a combined femoral and axillary perfusion strategy for the surgical treatment of type A aortic dissection. The purpose of this study was to review and clarify the clinical outcome of femoral artery cannulation combined with axillary artery cannulation for the treatment of Stanford type A aortic dissection.

Methods: We performed a retrospective study that included 327 patients who were surgically treated for type A aortic dissection in our institution from January 2017 to June 2019. Femoral and axillary artery cannulation was used to establish cardiopulmonary bypass in patients with type A aortic dissection. The demographic data, surgical data, and clinical results of the patients were calculated.

Results: Femoral artery combined with axillary artery cannulation was technically successful in 327 patients. The cardiopulmonary bypass time was $141.60 \pm 34.89 \mathrm{~min}$, and the selective antegrade cerebral perfusion time was $14.94 \pm 2.76$ min. The early mortality rate was $3.06 \%$. The incidence of permanent neurologic dysfunction was $0.92 \%$. Sixteen patients had postoperative renal insufficiency, and five patients had liver failure.

Conclusion: Femoral artery combined with axillary artery cannulation for type A aortic dissection can significantly improve the prognosis of patients, especially in terms of cerebral protection, and can reduce the occurrence of adverse malperfusion syndrome and neurological complications.
\end{abstract}

Keywords: Aortic dissection, Artery cannulation, Malperfusion

\section{Introduction}

Stanford type A aortic dissection (TAAD) is a surgical emergency with high rates of surgical complications and mortality $[1,2]$. The optimal cannulation strategy in surgery for TAAD is critical to patient survival but remains controversial [3-6]. Because the lesion mainly involves the ascending aorta and the aortic arch, the ascending

\footnotetext{
* Correspondence: gzlde0323@msn.com

† Ling-chen Huang and Qi-chen Xu contributed equally to this work. Ling-chen Huang and Qi-chen Xu are first author

Department of Cardiovascular Surgery, Union Hospital, Fujian Medical

University, Fuzhou 350001, People's Republic of China
}

aorta is often not suitable for cannulation to set up the extracorporeal circulation. Various cannulation techniques to establish cardiopulmonary bypass (CPB) for the emergency treatment of TAAD have been reported [7-9]. The femoral artery and the axillary artery have become common alternative cannulation sites. Each of these cannulation sites has its own advantages and disadvantages, and the selection strategy is often affected by the range of lesion involvement, surgical methods, peripheral vascular lesions and other factors. 
The femoral artery is the classic cannulation site for this kind of surgery. Femoral artery cannulation can be easily and safely performed before sternal opening. However, many people question the risk of increased mortality, neurological complications, lower limb ischaemia, malperfusion syndrome, embolism and other problems $[3,10]$.

Axillary artery cannulation can avoid these problems associated with femoral artery cannulation. In recent years, surgeons have begun to use axillary artery cannulation to treat TAAD due to malperfusion with traditional femoral artery cannulation. This type of cannulation provides effective cerebral protection, besides, aortic dissection is rarely involved the axillary artery to ensure the true lumen blood supply to the greatest extent, facilitating the implementation of anterograde selective cerebral perfusion for brain protection. The direction of physiological blood flow reduces malperfusion complications during $\mathrm{CPB}$ and allows anterograde cerebral perfusion during circulatory arrest. However, axillary artery cannulation still has some limitations, such as insufficient flow, which may affect the perfusion of organs $[11,12]$.

We have combined axillary artery cannulation with femoral artery cannulation to overcome the disadvantages of single cannulation. The strategy has been performed at our institution for more than ten years. This study reviewed the mortality and morbidity of TAAD in our hospital from January 2017 to June 2019 and analysed the safety and efficacy of our combined cannulation strategy.

\section{Materials and methods}

\section{Patients and methods}

The medical records, operative records, and discharge summaries of all patients who underwent TAAD surgery with combined cannulation at our institution from January 2017 to June 2019 were reviewed in an electronic medical record system and picture achieving and communication system. The records were reviewed, and cannulation sites, surgical procedures, and overall clinical outcomes were noted. We were particularly concerned about postoperative lower limb ischaemia, stroke, malperfusion, paraplegia, and death - complications that may be related to the cannulation site and retrograde perfusion.

The ethics committee of Union Hospital of Fujian Medical University approved this study protocol. Informed consent was waived due to the retrospective nature of the study.

\section{Surgical techniques}

All patients were placed supine under general anaesthesia. To avoid malperfusion, the following measures are taken to minimize the risk: 1 . the peripheral vascular condition was evaluated by computed tomography images to assess whether there was occlusive disease or dissection involvement; and 2. peripheral blood pressure monitoring and oxygen saturation detection were used to evaluate whether there was occlusive disease or dissection involvement. The affected arteries were not cannulated if significant stenosis or dissection were identified in the preoperative examinations.

We preferred right axillary artery combined with right femoral artery cannulation. The surgeons were divided into two groups and started at the same time. During femoral artery cannulation, after a purse-string suture was placed on the exposed femoral artery, a femoral arterial cannula was inserted into the femoral artery by using the modified Seldinger technique. The right femoral artery was usually cannulated if dissection was absent in the right iliofemoral artery. If both sides were dissected, we exercised great care to ensure that our cannula was placed into the true lumen.

If vital signs were stable, another group continued the procedure, and axillary artery exposure for cannulation was obtained through a $4-6 \mathrm{~cm}$ incision approximately $2 \mathrm{~cm}$ under the subclavian fossa. The fibres of the pectoralis major muscle were bluntly divided. The pectoralis minor muscle was retracted laterally. After exposing the axillary artery, femoral artery clamps were used proximal and distal to the cannulation site. While clamping the vessel and longitudinal arteriotomy, either direct cannulation with an arterial cannula or end-to-side anastomosis with a Dacron graft to the axillary artery with a running 5-0 Prolene suture was carried out. Flow was evaluated through the cannula by blood return, and if flow was sufficient, the cannula was connected to the arterial line and secured to the skin.

Median sternotomy was performed, and venous cannulation was performed with a 2-stage right atrial cannula or with superior and inferior vena cava cannulation in the case of a combined intracardiac operation. The arterial perfusion line was divided into two branches on the operating table, and the "single pump and double tube method" was adopted for management to transfer the arterial perfusion position and protect the cerebral tissue at different stages of the operation.

After cannulation, the cannulation position was confirmed by observing whether there was clear blood return, whether the pump pressure was normal, and whether there was a significant increase in the pump pressure after pumping $50 \sim 100 \mathrm{ml}$ of liquid to eliminate the possibility of insertion into the dissection. The arterial pressure of the radial and dorsal foot arteries as well as transesophageal echocardiography (TEE) and regional cerebral oxygen saturation were routinely monitored by an anaesthesiologist. 
After СРB was initiated, we routinely palpated the aorta and compared the pressures of the dorsal foot artery and radial artery, monitored regional cerebral oxygen saturation and evaluated the area ratio of the true lumen and false lumen in the descending aorta with TEE to evaluate whether there was malperfusion. If the patient was suspected of having intraoperative organ malperfusion due to cannulation of the arterial cannula into the false lumen, we changed the location of the arterial cannula.

During surgery, our brain protection methods were deep hypothermia concomitant with selective antegrade cerebral perfusion (SACP). Additionally, neuroprotective drugs were administered, and the head was cooled with a topical ice hat. The axillary artery was rarely dissected, so we could simply place the cannula inside the true lumen. After circulatory arrest was established, we routinely assessed the backflow in the orifice of the arch vessels and monitored regional cerebral oxygen saturation. If the backflow was reduced or the regional cerebral oxygen saturation value was decreased, we placed another cannula inside the orifice of the carotid artery to prevent decreased cerebral perfusion, which would lead to brain dysfunction $[13,14]$.

If the dissection involved only the ascending aorta, the ascending aorta and a hemi-arch replacement were routine used. For patients with aortic arch involvement, we usually used triple-branched stent-graft technology [15]. During the cooling phase of core body temperature, the innominate artery and the left common carotid artery were dissociated from the surrounding tissues. After the ascending aorta was clamped, aortic root manipulations such as aortic valve repair and aortic sinus reconstruction were performed, and then the Dacron tube graft was subsequently continuously anastomosed to the aortic root. When a $22^{\circ} \mathrm{C}$ rectal temperature was achieved, selective cerebral perfusion via the right axillary artery was started at a rate of 10 to $15 \mathrm{~mL} / \mathrm{kg} / \mathrm{min}$, and femoral artery perfusion was discontinued. With the innominate artery and left common carotid artery cross-clamped, the ascending aorta was transected at the base of the innominate artery. Then, the triple-branched stent graft was inserted and properly positioned. Finally, continuous end-to-end anastomosis was performed between the artificial vessels and intraoperative stents. After the dissection operation and after the air was carefully flushed out, systemic perfusion was resumed, and the patient was rewarmed [16-18].

\section{Definition of clinical parameters}

Early mortality was defined as all-cause mortality either in-hospital or within 30 days of surgery. Temporary neurologic dysfunction was defined as the presence of postoperative agitation, transient delirium, and confusion without focal neurologic symptoms. Permanent neurologic injury was defined as the new onset of permanent neurologic deficits, including coma or stoke after surgical repair with or without morphological correlates in a brain magnetic resonance or computed tomography image. Early stroke was defined as evident permanent neurologic injury after emergence from anaesthesia. Delayed stroke was defined as permanent neurologic injury after first awakening from surgery without neurological deficits. Acute kidney injury was defined as serum creatinine concentrations over $133 \mu \mathrm{mol} / \mathrm{l}$ or the need for dialysis due to oliguria. Postoperative liver failure was defined as the concurrent observation of at least two of the following parameters: coagulation abnormalities, total bilirubin $>15 \mathrm{mg} /$ $\mathrm{dL}$, liver enzyme levels more than tenfold the upper limit of normal, alteration of consciousness, and asterixis.

\section{Statistical analysis}

Statistical analysis was performed with SPSS ver. 22.0 (SPSS Inc., Chicago, IL, USA). Nonnormally distributed data were expressed as medians. Continuous variables with a normal distribution were expressed as the mean \pm standard distribution.

\section{Results}

A total of 327 patients underwent surgical repair for TAAD in our institution between January 2017 and June 2019. There were 253 males and 74 females with a mean age of $52.16 \pm 11.72$ years (range, 22 to 87 years). There were 261 patients $(79.82 \%$ ) with hypertension and 28 patients $(8.56 \%)$ with diabetes. The mean BMI was $24.21 \pm$ $1.92 \mathrm{~kg} / \mathrm{m}^{2}$.

The location of the primary intimal tear was the ascending aorta in 219 patients (66.97\%), the arch in 40 $(12.23 \%)$, and the distal end of the left subclavian artery in 37 (11.31\%); no obvious intimal tear was found in 31 $(9.48 \%)$ patients. The false lumen involved the innominate artery in 49 patients (14.98\%), the left common carotid artery in 37 patients (11.31\%), the left subclavian artery in 31 patients $(9.48 \%)$, the celiac trunk in 113 patients $(34.56 \%)$, the superior mesenteric artery in $60 \mathrm{pa}-$ tients (18.35\%), the right renal artery in 90 patients (27.52\%), and the left renal artery in 105 patients (32.11\%). These lesions were diagnosed on preoperative computed tomography scans and were partly confirmed at surgery.

The ejection fraction was $62.76 \pm 7.63 \%$. Echocardiography showed 19 cases of moderate pericardial effusion (5.81\%). Massive pericardial effusion that led to pericardial tamponade was noted in 5 patients $(1.53 \%)$. There were 170 patients $(51.99 \%)$ with mild aortic insufficiency, 116 patients (35.47\%) with moderate aortic insufficiency, and 41 patients (12.54\%) with severe aortic insufficiency. Coronary artery involvement was observed in a total of 
11 patients (3.36\%) before surgery, and regional wall motion abnormalities were identified in 17 patients $(5.20 \%)$ with echocardiography.

In seven patients (2.14\%), preoperative neurologic symptoms such as transient ischaemic attack and transient drowsy mentality developed. Eleven patients had preoperative renal insufficiency, and four patients had hepatic insufficiency. Two patients suffered from paraplegia. The clinical characteristics of the patients are detailed in Table 1.

The ascending aorta was replaced in all cases. The most frequent extent of aortic replacement was the ascending aorta and hemiarch replacement combined with

Table 1 Demographic and clinical data

\begin{tabular}{|c|c|}
\hline Item & Data \\
\hline Male/Female & $253 / 74$ \\
\hline Age (years) & $52.16 \pm 11.72$ \\
\hline BMI $\left(\mathrm{kg} / \mathrm{m}^{2}\right)$ & $24.21 \pm 1.92$ \\
\hline Hypertension ( $n, \%)$ & $261(79.82 \%)$ \\
\hline Diabetes $(n, \%)$ & $28(8.56 \%)$ \\
\hline LVEF (\%) & $62.76 \pm 7.63 \%$ \\
\hline \multicolumn{2}{|l|}{ location of intimal tear $(n, \%)$} \\
\hline ascending aorta & $219(66.97 \%)$ \\
\hline aortic arch & $40(12.23 \%)$ \\
\hline descending aorta & $37(11.31 \%)$ \\
\hline without obvious intimal tear & $31(9.48 \%)$ \\
\hline \multicolumn{2}{|l|}{ Artery involved by the false lumen $(n, \%)$} \\
\hline Innominate artery & 49 (14.98\%) \\
\hline left common carotid artery & $37(11.31 \%)$ \\
\hline the left subclavian artery & $31(9.48 \%)$ \\
\hline Celiac trunk artery & $113(34.56 \%)$ \\
\hline superior mesenteric artery & $60(18.35 \%)$ \\
\hline right renal artery & $90(27.52 \%)$ \\
\hline left renal artery & $105(32.11 \%)$ \\
\hline Pericardial tamponade $(n, \%)$ & $5(1.53 \%)$ \\
\hline \multicolumn{2}{|l|}{ Aortic insufficiency $(n, \%)$} \\
\hline mild & $170(51.99 \%)$ \\
\hline moderate & $116(35.47 \%)$ \\
\hline severe & $41(12.54 \%)$ \\
\hline Observed Coronary artery involved ( $n, \%)$ & $11(3.36 \%)$ \\
\hline Regional wall motion abnormalities $(n, \%)$ & $17(5.20 \%)$ \\
\hline Neurologic Symptoms ( $n, \%)$ & $7(2.14 \%)$ \\
\hline Cardiac tamponade $(n, \%)$ & $13(3.98 \%)$ \\
\hline Renal insufficiency $(n, \%)$ & $11(2.36 \%)$ \\
\hline Hepatic insufficiency $(n, \%)$ & $4(1.22 \%)$ \\
\hline Paraplegia ( $n, \%)$ & $2(0.61 \%)$ \\
\hline Transient leg ischemia $(n, \%)$ & $3(0.92 \%)$ \\
\hline
\end{tabular}

modified triple-branched stent-graft implantation for the repair of TAAD. The detailed operative procedures are shown in Table 2. For proximal repair, supracoronary anastomosis was performed in 120 patients (36.70\%), root reconstruction was performed in 171 patients (55.35\%) in whom the aortic valve could be preserved, and aortic valve replacement was performed in 36 patients $(11.00 \%)$. A coronary artery bypass graft was performed in 11 (3.36\%) patients.

The CPB time was 90 to 334 min (mean, $141.60 \pm$ $34.89 \mathrm{~min}$ ), the cross-clamp time was 22 to $169 \mathrm{~min}$ (mean, $49.05 \pm 20.16 \mathrm{~min}$ ), and the selective cerebral perfusion and lower body arrest time was 7 to $25 \mathrm{~min}$ (mean, 14.94 $\pm 2.76 \mathrm{~min}$ ). Sixty-five patients had unilateral selective cerebral perfusion, and 262 had bilateral selective cerebral perfusion.

The postoperative consciousness time and mechanical ventilation time after the operation were $6.71 \pm 2.35$ and $17.29 \pm 2.10 \mathrm{~h}$, respectively. The postoperative length of stay in the intensive care unit was $55.41 \pm 10.16 \mathrm{~h}$. No patient died during the operation. There were 10 (3.06\%) early deaths. Three patients died of sepsis on postoperative days 7, 21, and 23. The other five patients died of multiorgan failure. One patient had a low postoperative cardiac output with extracorporeal membrane oxygenation (ECMO) support and died on postoperative day 5 . Another patient died of haemorrhagic stroke on postoperative day 30. Eight patients were treated surgically but were discharged from hospital before fully recovery and were lost to follow-up. Transient neurologic dysfunction was observed in 15 patients (4.59\%), and all patients recovered before hospital discharge. A total of 3 patients (0.92\%) suffered from permanent neurologic dysfunction. Haemorrhagic and ischaemic stroke was observed

Table 2 Intra-operative data

\begin{tabular}{ll}
\hline Item & Data \\
\hline $\begin{array}{l}\text { Surgery strategy } \\
\text { Hemiarch replacement }(n, \%)\end{array}$ & $16(4.89 \%)$ \\
$\quad$ Modified triple-branched implantation $(n, \%)$ & $311(95.11 \%)$ \\
Proximal repair & \\
$\quad$ Supracoronary anastomosis alone & $120(36.70 \%)$ \\
Aortic valve replacement & $36(11.00 \%)$ \\
Root reconstruction & $171(55.35 \%)$ \\
Coronary artery bypass graft & $11(3.36 \%)$ \\
Cardiopulmonary bypass time (min) & $141.60 \pm 34.89$ \\
Cross-clamping time (min) & $49.05 \pm 20.16$ \\
Selective cerebral perfusion time (min) & $14.94 \pm 2.76$ \\
Cerebral perfusion strategy & \\
Unilateral $(n, \%)$ & $65(19.88 \%)$ \\
Bilateral $(n, \%)$ & $262(80.12 \%)$ \\
\hline
\end{tabular}


in one patient and two patients, respectively. Two patients with preoperative paraplegia also had paraplegia postoperatively. Five patients with preoperative cerebral malperfusion recovered without postoperative neurologic deficits or sequelae. Sixteen patients experienced postoperative haemodialysis-dependent renal failure (4.89\%). Five cases of postoperative acute liver failure were documented (1.53\%). No patients required repeat surgery to correct excessive postprocedural bleeding. Lower limb ischaemia occurred in 3 patients $(0.92 \%)$. No patients had permanent cannulation-related complications. All related postoperative complications are shown in Table 3.

\section{Discussion}

The main finding of our study was that the early clinical outcome of patients undergoing surgical repair for type A aortic dissection with a combined femoral and axillary perfusion strategy in our institution was similar with that of patients with other cannulation strategy. Our 30-day mortality rate and other adverse complications are similar to associations reported in other studies [17-21].

Surgical repair of type A aortic dissection is associated with high mortality and high complication morbidity. Establishing CPB that maintains adequate systemic perfusion is essential to prevent end-organ hypoperfusion during the procedure. Femoral artery cannulation and axillary artery cannulation to establish extracorporeal circulation are widely used in clinical practice and have been extensively reported in previous literature [22-24].

The femoral artery has been used as the primary cannulation site for $\mathrm{CPB}$ in cardiac surgery for more than 40 years $[25,26]$. Several studies have shown that retrograde perfusion of the femoral artery has the following deficiencies: (1) a "live valve" effect and false lumen blood supply, leading to central nervous system, upper arm, kidney and abdominal organ perfusion disorders; (2) a false lumen blood supply and retrograde blood flow flush atherosclerotic plaques on the vascular wall, leading to embolization and an increase in the incidence of

Table 3 Postoperative Data

\begin{tabular}{ll}
\hline Item & TA group \\
\hline Early Mortality & $10(3.06 \%)$ \\
Postoperative consciousness time (hours) & $6.71 \pm 2.35$ \\
Mechanical ventilation time (hours) & $17.29 \pm 2.10$ \\
ICU stay (hours) & $55.41 \pm 10.16$ \\
Transient neurologic dysfunction $(n, \%)$ & $15(4.59 \%)$ \\
Permanent neurologic dysfunction $(n, \%)$ & $3(0.92 \%)$ \\
Hemodialysis-dependent renal failure $(n, \%)$ & $16(4.89 \%)$ \\
Liver failure $(n, \%)$ & $5(1.53 \%)$ \\
Lower limb ischemia $(n, \%)$ & $3(0.92 \%)$ \\
\hline
\end{tabular}

stroke; (3) compared with that of the axillary artery, femoral artery cannulation is easily affected by atherosclerosis or dissection; (4) lower limb ischaemia; and (5) the inconvenience of anterograde selective cerebral perfusion $[27,28]$.

Since 1995, axillary artery cannulation has been used as an alternative to femoral artery cannulation in patients with TAAD [29]. Compared with femoral artery cannulation, axillary artery cannulation can significantly reduce central nervous system complications in patients with deep hypothermia. Anterograde selective cerebral perfusion is considered to be the most ideal method for cerebral protection at present, and axillary artery cannulation can be very convenient for coordinating brain protection, which greatly reduces the side effects resulting from deep hypothermia and circulatory arrest (DHCA). Yoshimasa Moizumi believes that antegrade perfusion through the axillary artery can avoid the disadvantages of retrograde perfusion, such as organ malperfusion caused by floating dissected intima flaps or expanding false lumens. In his study, 69 patients (65.09\%) underwent cannulation of the axillary artery, and the results demonstrated decreased hospital mortality [30, 31]. In addition, the advantages of axillary artery cannulation are also shown in the following aspects. 1. There is rich collateral circulation of the neck and shoulder. A Chinese study showed that $17 \%$ of patients have an incomplete anterior and posterior circle of Willis. A complete circle of Willis configuration was only found in $27 \%$ of the Chinese population, and $56 \%$ had a partially complete circle of Willis [32]. 2. Axillary artery cannulation is not easily affected by atherosclerosis or dissection. 3. Axillary artery cannulation avoids retrograde embolism and expansion of the dissection. 4. Axillary artery cannulation facilitates selective cerebral perfusion.

One disadvantage of axillary artery cannulation is that it takes more time to construct. However, Budde et al. used axillary artery cannulation to establish CPB in 61 patients undergoing elective and emergency surgery due to proximal aortic pathology. There were no significant differences in postoperative neurological dysfunction or mortality between the selective group and the emergency group. They claimed that the routine use of axillary artery cannulation in emergent cases was just as safe and efficacious as its use in the elective setting [33]. However, the biggest disadvantage of axillary artery cannulation is insufficient flow, which may affect the perfusion of organs [12].

Our centre used femoral artery combined with axillary artery cannulation to establish extracorporeal circulation, providing reliable circulation support for TAAD repair. Few studies have examined the clinical outcomes of this cannulation strategy. In this study, 96.94\% (317/327) of the patients undergoing femoral and axillary artery 
cannulation survived. In addition, the incidences of permanent neurologic dysfunction, renal insufficiency, liver failure and lower limb ischaemia were 0.92, 4.89, 1.53 and $0.92 \%$, respectively. Based on the results of our institution, we conclude that femoral artery combined with axillary artery cannulation results in satisfactory shortterm outcomes.

With the combination of femoral artery and axillary artery cannulation, with this single pump and double tube method, the true lumen of TAAD can be fully perfused to the greatest extent during $\mathrm{CPB}$, avoiding poor systemic perfusion. In addition, anterograde cerebral perfusion can also be carried out through the upper body during circulatory arrest, which greatly ensures cerebral perfusion and reduces the incidence of cerebral complications [34].

\section{Conclusion}

Femoral artery combined with axillary artery cannulation for Stanford type A AD can significantly improve the prognosis of patients, especially in terms of cerebral protection, and can reduce the occurrence of adverse malperfusion syndrome.

\section{Abbreviations}

TAAD: Type A Aortic dissection; TEE: Transesophageal echocardiography; CPB: Cardiopulmonary bypass; SACP: Selective antegrade cerebral perfusion; DHCA: Deep hypothermia and circulatory arrest; ECMO: Extracorporeal membrane oxygenation

\section{Acknowledgements}

We highly acknowledge the contributions of the participating doctors: Xueshan Huang, Feng Lin, Qi-min Wang, Han-fan Qiu, and Dong-shan Liao.

\section{Authors' contributions}

Ling-chen Huang and Qi-chen Xu contributed equally to this study and share first authorship. L-WC, L-CH and Q-CX designed the study, participated in the operation, and drafted the manuscript. Q-CX and Ls-CH collected the clinical data and performed the statistical analysis. X-FD and D-ZC provided technical support. All authors read and approved the final manuscript.

\section{Funding}

There is no financial support for this work.

\section{Availability of data and materials}

Data sharing was not applicable to this article, as no data sets were generated or analysed during the current study.

\section{Ethics approval and consent to participate}

This study complied with the requirements of the Ethics Committee of Fujian Medical University and adhered to the Declaration of Helsinki. Informed consent was waived due to the retrospective nature of the study.

\section{Consent for publication}

Not applicable.

\section{Competing interests}

The authors declare that they have no competing interests.
Received: 6 August 2020 Accepted: 2 November 2020

Published online: 10 November 2020

\section{References}

1. Nienaber CA, Clough RE. Management of acute aortic dissection. Lancet 2015:385:800-11.

2. Rampold V, Trimarchi S, Eagle KA, Nienaber CA, Oh JK, Bossone E, et al. Simple risk models to predict surgical mortality in acute type a aortic dissection: the international registry of acute aortic dissection score. Ann Thorac Surg. 2007:83:55-61.

3. Ren Z, Wang Z, Hu R, et al. Which cannulation (axillary cannulation or femoral cannulation) is better for acute type a aortic dissection repair? A meta-analysis of nine clinical studies. Eur J Cardiothorac Surg. 2015;47(3): 408-15.

4. Benedetto $U$, Mohamed $H$, Vitulli $P$, Petrou M. Axillary versus femoral arterial cannulation in type a acute aortic dissection: evidence from a meta-analysis of comparative studies and adjusted risk estimates. Eur J Cardiothorac Surg. 2015:48(6):953-9.

5. Ayyash B, Tranquilli M, Elefteriades JA. Femoral artery cannulation for thoracic aortic surgery: safe under transesophageal echocardiographic control. J Thorac Cardiovasc Surg. 2011;142(6):1478-81.

6. Fusco DS, Shaw RK, Tranquilli M, Kopf GS, Elefteriades JA. Femoral cannulation is safe for type a dissection repair. Ann Thorac Surg. 2004;78(4): 1285-9.

7. Wada S, Yamamoto S, Honda J, Hiramoto A, Wada H, Hosoda Y. Transapical aortic cannulation for cardiopulmonary bypass in type a aortic dissection operations. J Thorac Cardiovasc Surg. 2006;132(2):369-72.

8. Di Eusanio M, Ciano M, Labriola G, Lionetti G, Di Eusanio G. Cannulation of the innominate artery during surgery of the thoracic aorta: our experience in 55 patients. Eur J Cardiothorac Surg. 2007;32(2):270-3.

9. Minatoya K, Karck M, Szpakowski E, Harringer W, Haverich A. Ascending aortic cannulation for Stanford type a acute aortic dissection: another option. J Thorac Cardiovasc Surg. 2003 Apr;125(4):952-3.

10. Tiwari KK, Murzi M, Bevilacqua S, Glauber M. Which cannulation (ascending aortic cannulation or peripheral arterial cannulation) is better for acute type a aortic dissection surgery? Interact Cardiovasc Thorac Surg. 2010;10(5):797-802.

11. Neri $E$, Massetti M, Capannini $G$, et al. Axillary artery cannulation in type a aortic dissection operations. J Thorac Cardiovasc Surg. 1999;118(2):324-9.

12. Schachner T, Nagiller J, Zimmer A, Laufer G, Bonatti J. Technical problems and complications of axillary artery cannulation. Eur J Cardiothorac Surg. 2005:27(4):634-7.

13. Bachet J. What is the best method for brain protection in surgery of the aortic arch? Selective antegrade cerebral perfusion. Cardiol Clin. 2010;28(2): 389-401.

14. Lin Y, Chen MF, Chen LW, Wang JB, Zhang H, Li RM. Midterm cerebral outcomes of Stanford type a aortic dissection in patients who underwent novel triple-branched stent graft implantation combined with intraoperative monitoring of regional cerebral oxygen saturation. J Card Surg. 2019;34(9): 774-81.

15. Chen LW, Dai XF, Zhang GC, Lu L. Total aortic arch reconstruction with open placement of triple-branched stent graft for acute type A dissection. J Thorac Cardiovasc Surg. 2010;139(6):1654-5 e1.

16. Chen LW, Dai XF, Lu L, Zhang GC, Cao H. Extensive primary repair of the thoracic aorta in acute type a aortic dissection by means of ascending aorta replacement combined with open placement of triple-branched stent graft: early results. Circulation. 2010;122(14):1373-8.

17. Chen LW, Lu L, Dai XF, et al. Total arch repair with open triple-branched stent graft placement for acute type a aortic dissection: experience with 122 patients. J Thorac Cardiovasc Surg. 2014:148(2):521-8.

18. Chen LW, Dai XF, Wu XJ, et al. Ascending aorta and Hemiarch replacement combined with modified triple-branched stent graft implantation for repair of acute DeBakey type I aortic dissection. Ann Thorac Surg. 2017;103(2):595-601.

19. Westaby S, Saito S, Katsumata T. Acute type a dissection: conservative methods provide consistently low mortality. Ann Thorac Surg. 2002;73(3): 707-13.

20. Preventza O, Bakaeen FG, Stephens EH, Trocciola SM, de la Cruz Kl, Coselli JS. Innominate artery cannulation: an alternative to femoral or axillary cannulation for arterial inflow in proximal aortic surgery. J Thorac Cardiovasc Surg. 2013;145(3 Suppl):S191-6.

21. Preventza O, Garcia A, Tuluca A, Henry M, Cooley DA, Simpson K, Bakaeen FG, Cornwell LD, Omer S, Coselli JS. Innominate artery cannulation for 
proximal aortic surgery: outcomes and neurological events in 263 patients. Eur J Cardiothorac Surg. 2015;48(6):937-42 discussion 942.

22. Gulbins H, Pritisanac A, Ennker J. Axillary versus femoral cannulation for aortic surgery: enough evidence for a general recommendation? Ann Thorac Surg. 2007;83(3):1219-24.

23. Abe T, Usui A. The cannulation strategy in surgery for acute type a dissection. Gen Thorac Cardiovasc Surg. 2017;65(1):1-9.

24. Parikh N, Trimarchi S, Gleason TG, et al. Changes in operative strategy for patients enrolled in the international registry of acute aortic dissection interventional cohort program. J Thorac Cardiovasc Surg. 2017;153(4):S74-9.

25. Lillehei CW, Cardozo RH. Use of median sternotomy with femoral artery cannulation in open cardiac surgery. Surg Gynecol Obstet. 1959;108(6):706-14.

26. Berger RL, Saini VK, Dargan EL. Clinical applications of femoral vein-to-artery cannulation for mechanical cardiopulmonary support and bypass. Ann Thorac Surg. 1973;15(2):163-9.

27. Westaby S, Katsumata T, Vaccari G. Arch and descending aortic aneurysms: influence of perfusion technique on neurological outcome. Eur J Cardiothorac Surg. 1999;15(2):180-5.

28. Pappas G, Starzl TE. Retrograde false channel perfusion: a complication of cardiopulmonary bypass during repair of dissecting aneurysms. Ann Thorac Surg. 1970;9(3):263-6.

29. Sabik JF, Lytle BW, McCarthy PM, Cosgrove DM. Axillary artery: an alternative site of arterial cannulation for patients with extensive aortic and peripheral vascular disease. J Thorac Cardiovasc Surg. 1995;109(5):885-91.

30. Moizumi Y, Motoyoshi N, Sakuma K, Yoshida S. Axillary artery cannulation improves operative results for acute type a aortic dissection. Ann Thorac Surg. 2005;80(1):77-83

31. Numata S, Ogino H, Sasaki H, et al. Total arch replacement using antegrade selective cerebral perfusion with right axillary artery perfusion. Eur J Cardiothorac Surg. 2003;23(5):771-5.

32. Li Q, Li J, Lv F, Li K, Luo T, Xie P. A multidetector CT angiography study of variations in the circle of Willis in a Chinese population. J Clin Neurosci. 2011;18:379-83.

33. Budde JM, Serna DL Jr, Osborne SC, Steele MA, Chen EP. Axillary cannulation for proximal aortic surgery is as safe in the emergent setting as in elective cases. Ann Thorac Surg. 2006;82(6):2154-60.

34. Qiu ZH, Chen LW, Liao LM, Xiao J, Dai XF, Fang GH, Yan LL, Wu QS, Luo QF. Efficiency of modified triple-branched stent graft in type I aortic dissection: two-year follow-up. Ann Thorac Surg. 2020;110(3):925-32.

\section{Publisher's Note}

Springer Nature remains neutral with regard to jurisdictional claims in published maps and institutional affiliations.

Ready to submit your research? Choose BMC and benefit from:

- fast, convenient online submission

- thorough peer review by experienced researchers in your field

- rapid publication on acceptance

- support for research data, including large and complex data types

- gold Open Access which fosters wider collaboration and increased citations

- maximum visibility for your research: over $100 \mathrm{M}$ website views per year

At $\mathrm{BMC}$, research is always in progress.

Learn more biomedcentral.com/submissions 